Journal of Mechanical Engineering and Sciences (JMES)

ISSN (Print): 2289-4659; e-ISSN: 2231-8380; Volume 5, pp. 652-661, December 2013

(C) Universiti Malaysia Pahang, Malaysia

DOI: http://dx.doi.org/10.15282/jmes.5.2013.12.0063

\title{
DRYING OF EMPTY FRUIT BUNCHES AS WASTED BIOMASS BY HYBRID SOLAR-THERMAL DRYING TECHNIQUE
}

\author{
H. H. Al-Kayiem ${ }^{1, *}$ and Y. Md Yunus ${ }^{2}$ \\ ${ }^{1}$ Mech. Eng. Dept., Universiti Teknologi PETRONAS, Bandar Seri Iskandar, \\ 31750 Tronoh, Perak, Malaysia. \\ *Phone: +6053687008, Fax: +6053656461; \\ *Email: hussain_kayiem@petronas.com.my \\ ${ }^{2}$ Mechanical Engineer, Field Engineer, Ranhill Worley Parsons Sdn. Bhd
}

\begin{abstract}
Solar drying of EFB is highly feasible and economic, but the solar drying process is interrupted during cloudy or rainy days and also at night. In the present paper, a combined solar, as the main heat input, and biomass burner, as an auxiliary source of thermal energy, has been investigated experimentally to dry EFB. An experimental model consisting of a solar dryer integrated with a thermal backup unit was designed and fabricated. A series of experimental measurements were carried out in four different drying modes, namely, open sun, mixed direct and indirect solar, thermal backup, and hybrid. The results from the four modes used to dry $2.5 \mathrm{~kg}$ of EFB were summarized and compared. The results indicated that the solar drying mode required around 52 to 80 hours to dry the EFB, while the open sun drying mode required 100 hours. Usage of the thermal backup as heat source reduced the drying time to 48-56 hours. With the hybrid mode, the drying time was considerably reduced to 24-32 hours. The results demonstrate that the combined solar and thermal backup effectively enhanced the drying performance. The application of a solar dryer with a biomass burner is practical for massive production of solid fuels from EFB.
\end{abstract}

Keywords: solar dryer, hybrid solar dryer, biomass drying, EFB, palm oil solid waste, thermal backup.

\section{INTRODUCTION}

Malaysia's palm oil industry currently operates more than 300 palm oil mills that process palm oil from 2.5 million hectares of oil palm estates throughout the country and produce more than a million metric tons of EFB as waste material every year (Chua, 1991). The palm oil industry commonly uses its own solid waste, shell and EFB fiber as boiler fuel. The EFB is also burnt inside the incinerators to produce potash ash which is applied in the plantation as fertilizer. The stability and strength characteristics of EFB fibers have led to their application in mattress and cushion manufacturing, soil stabilization/compaction for erosion control, landscaping and horticulture, ceramic and brick manufacturing and flat fiber board manufacturing (Hasibuan \& Daud, 2007). The power plant boiler requires nonstop operation. Brammer and Bridgwater (1999) stated that due to the continuous running of an engine or turbine, for example, in bio-energy plants, the biomass may have to be dried. This has been used widely in palm oil mills, sawmills and wood processing factories to generate both electricity and steam and it can be transformed into both heat and electricity simultaneously through cogeneration.

$\mathrm{EFB}$, as a solid waste product from the palm oil industry, is found to be very wet in its raw state, but is excellent for power boilers after drying. The EFB needs to be 
dried before proceeding to further processes, and here the application of a solar dryer with a biomass burner is practical since it provides a high drying rate which consequently increases the production. According to Rahim and Suffian (2006) the initial moisture content of EFB is $80 \%$ and the optimum moisture content is less than $13 \%$ for combustion. Among EFB fiber drying technologies that have been applied are a conventional rotary drum dryer with a flue gas drying medium from a diesel burner and superheated steam (Hasibuan \& Daud, 2007). FASC Malaysia has installed a KDS machine in the 14 MWe TSH Biomass Power Plant in Kunak, Malaysia, for the purpose of drying EFB (Mannan, 2008). Due to the high cost of diesel fuel, there is increasing demand on a commercial scale for biomass fuels since biomass is cheaper and available in abundant quantity. The rising utilization and high dependence on electricity to dry EFB fibers is expected to be reduced by using solar energy as the source of heat. However, one major problem which exists with these solar dryers is their capability to dry products only when solar energy is available, so enabling them to be operated only on hot days. This causes inconsistency in drying and a decrease in the production scale. To solve this problem, the usage of biomass as the fuel of the burner is almost a synonym in the drying industry. This burner extends the drying process during cloudy or rainy days (backup heater) and even during the day and night. Several researchers have studied the use of solar dryers with biomass burners. Biomass may be obtained from forests, woods and agricultural lands and is commonly burned using inefficient technologies in most developing countries. Malaysia is one country which is taking advantage of its enormous output of biomass from oil palm residues and wood wastes. At present, biomass fuels account for about $16 \%$ of the energy consumption in the country, of which $51 \%$ is from palm oil biomass and $22 \%$ from wood waste (Energy Information Bureau (EIB) Malaysia). A biomass backup heater is used to supplement the heat required for a faster drying process (Bena \& Fuller, 2002). Among the biomass fuel materials that have been reported in biomass burner applications are coconut shells (Serafica \& del Mundo, 2005), woodchips (Madhlopa \& Ngwalo, 2007), charcoal, paddy husk (Thanaraj, Dharmasena, \& Samarajeewa, 2004), fuel wood (Bena \& Fuller, 2002; Prasad, Vijay, Tiwari, \& Sorayan, 2006; Tarigan \& Tekasakul, 2005) and briquetted rice husk (Mastekbayeva, Chandika, Augustus, \& Kumar, 1999). The biomass materials may have to be dried first in order to support the continuous running of an engine and turbine (Brammer \& Bridgwater, 1999). Hence, solar and biomass are the two main renewable sources of energy that are extremely suitable for drying application.

Few researchers have studied and fabricated solar dryers specifically for EFB drying. Hasibuan and Daud (2007) applied hot flue gases in a diesel-fired rotary drum dryer for drying EFB. However, the drying resulted in low quality, with the EFB product suffering from over-drying, browning and dust explosions. It can be concluded that the heat from direct fuel is more applicable for drying biomass product. The heat from direct fuel is expected to be higher than indirect fuel. By controlling the indirect heat for food drying, the direct heat temperature is assumed to be not too high and is therefore suitable to be applied for the drying of biomass product. The range of supplied temperatures should be observed first to prevent over-drying. The effect of dust explosions can be avoided by using a filter placed in between the burner and solar dryer. Sulaiman, Abdullah, and Aliasak (2013) used a solar dryer comprising six double-pass solar collectors with porous medium in the second pass. These were fabricated and connected in a series of three collectors in two banks and a drying chamber. The system 
successfully dried the EFB from an initial moisture content of $170.68 \mathrm{mf} w t \%$ to a final moisture content $4.36 \mathrm{mf} w \mathrm{t} \%$ in 66 hours of solar exposure.

The objective of this study is to investigate the performance of the developed hybrid solar dryer integrated with a thermal backup unit (TBU). The thermal backup biomass burner was used to create a 24-hour drying process. The system was used for drying EFB in four different operational modes. The results are compared in terms of the drying period for $2.5 \mathrm{~kg}$ of the EFB. Also, the drying performance is used as a comparison tool between the four cases. In addition, detailed discussion of the drying performance at each of the five tray levels is included in the paper.

\section{MATERIAL AND METHODS}

The present investigations are carried out experimentally. The experimental implementations consist of the solar dryer, the thermal backup unit, the measuring instruments and the measurements procedure. Each is discussed separately in the following paragraphs.

\section{Solar Dryer Model}

The entire body of the dryer is made of $4 \mathrm{~mm}$ thickness Perspex to allow as much direct solar radiation as possible to penetrate to the inside of the drying chamber. The base is made of $1.0 \mathrm{~m}$ long x $1.0 \mathrm{~m}$ wide plywood having $10 \mathrm{~mm}$ thickness. The total height of the dryer model is $1000 \mathrm{~mm}$ and the base dimensions are $900 \mathrm{~mm} \times 900 \mathrm{~mm}$ fixed on the wood base. A $2 \mathrm{~m}$ height chimney made of $102.0 \mathrm{~mm}$ dia. PVC pipe is installed at the upper part of the dryer to enhance the drafting of the moist air from inside the drying chamber. Two aluminum corrugated plates painted in matte black are installed at the base. The plates are inclined at $15^{\circ}$ such that the lower part of both is at the center of the drying chamber. A slot is left between the plates to permit heated air from underneath the absorber plates to flow up to the trays. The dryer and the absorber plate were designed under the assumption that near collector the air temperature, $T_{1}$ was around $60 \pm 5^{\circ} \mathrm{C}$ with the surrounding temperature outside the dryer, $T_{a m b}$ of $30^{\circ} \mathrm{C}$. The selected drying temperature, $T_{\text {chamber }}$ of 50 to $65^{\circ} \mathrm{C}$ is suitable for drying all types of product and is able to inactivate the growth of microorganisms. The assumed outlet dryer temperature, $T_{o d}$ was $35^{\circ} \mathrm{C}$, which was slightly low, since it contained the picked up moisture content. The sizes of the absorber plate and the drying chamber are designed according to the mentioned temperatures and the fabricated model is shown in Figure 1. The details of the conceptual design and design calculation procedure are outlined in (Yunus, 2011).

\section{Thermal Backup Unit}

The basic function of the thermal backup unit (TBU) is to supply working fluid at $60^{\circ} \mathrm{C}$ to $70^{\circ} \mathrm{C}$ at the outlet from the gas-to-gas heat exchanger. This range is expected to provide an ambient temperature inside the drying chamber within the selected drying temperature of $50^{\circ} \mathrm{C}$ to $65^{\circ} \mathrm{C}$. This temperature is the optimum for the drying of many types of products, ranging from food to herbs to fish and solid agriculture wastes. In particular, for the drying of the $\mathrm{EFB}$, the temperature may be as high as $65^{\circ} \mathrm{C}$. A similar TBU has not been found in the literature. It comprises a burner unit in the lower part and a gas-to-gas heat exchanger (G-to-G HEX) in the upper part. 


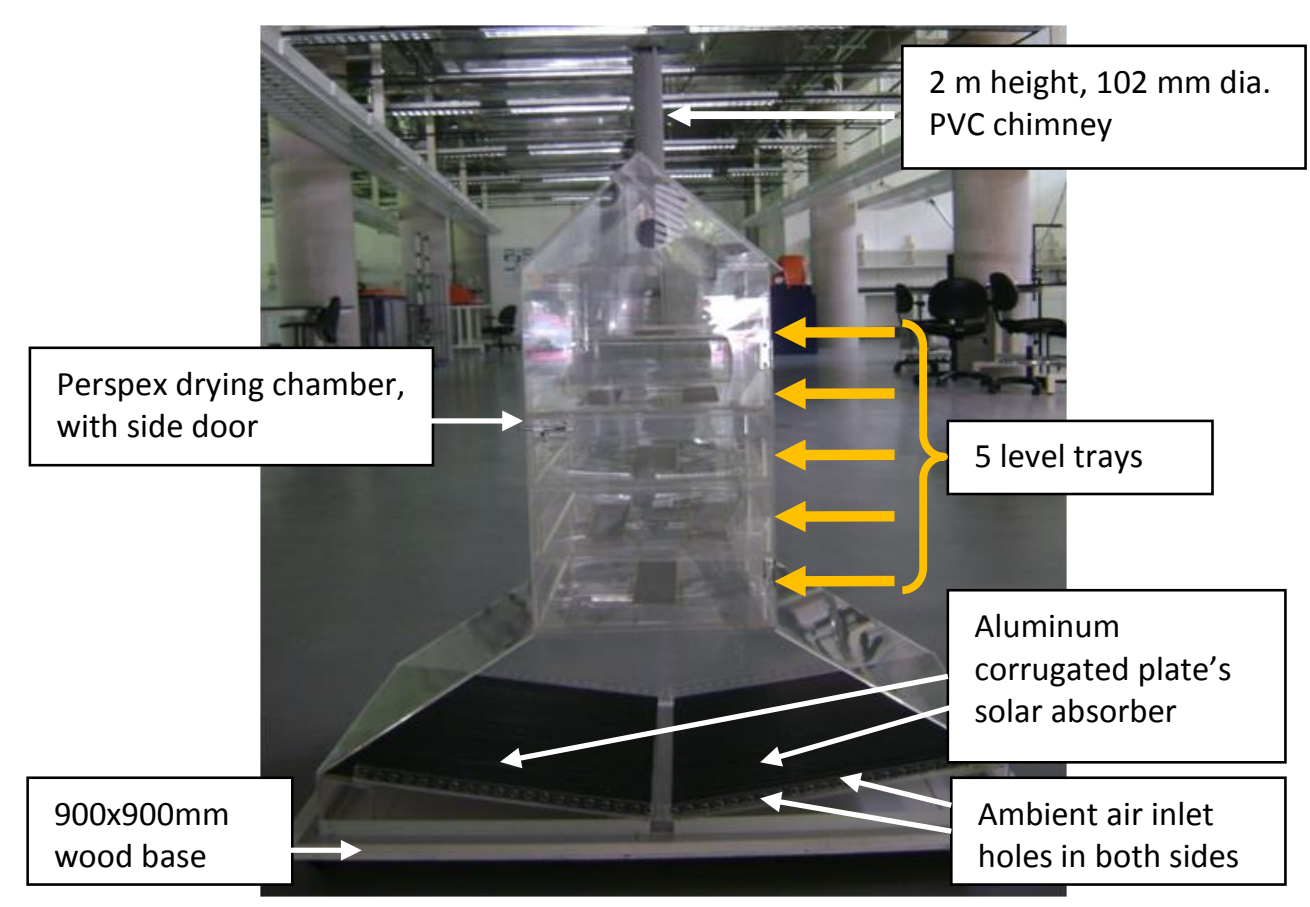

Figure 1. Parameter assumptions of the solar dryer

The solid fuel mixture of wood chips and EFB was dropped from a feeding container and positioned on a steel mesh in the burner. The produced flue flows up through a specially designed passage to exchange heat with the air flow which enters at the lower part of the G-to-G HEX from outside at an ambient temperature of around $30^{\circ} \mathrm{C}$. The air moves up under the effect of natural convection and discharges through the outlet at the top of the G-to-G HEX. The design procedure of the TBU is presented in detail by Yunus, Al-Kayiem, and Albaharin (2011). A sketch of the TBU is shown in Figure 2.

\section{Drying Procedure and Measurements}

The parameters measured during the experiment were temperature, relative humidity, weights of the biomass fuel and the product to be dried, speed of air flow and solar irradiation. The relative humidity and air temperature inside the chamber were measured using a digital hygrometer/psychrometer (NPI 597) with an accuracy of $2 \%$ of the reading, while the absorber temperature was recorded using thermocouple probes, with $\pm 0.2^{\circ} \mathrm{C}$ accuracy, connected to a 24-channel data logger type Fluke Hydra. A solarimeter type SL 200 Kimo instrument with $5 \%$ of measured value accuracy was used to measure the solar radiation, and an anemometer (Testo 435) was used for the airflow velocities. 


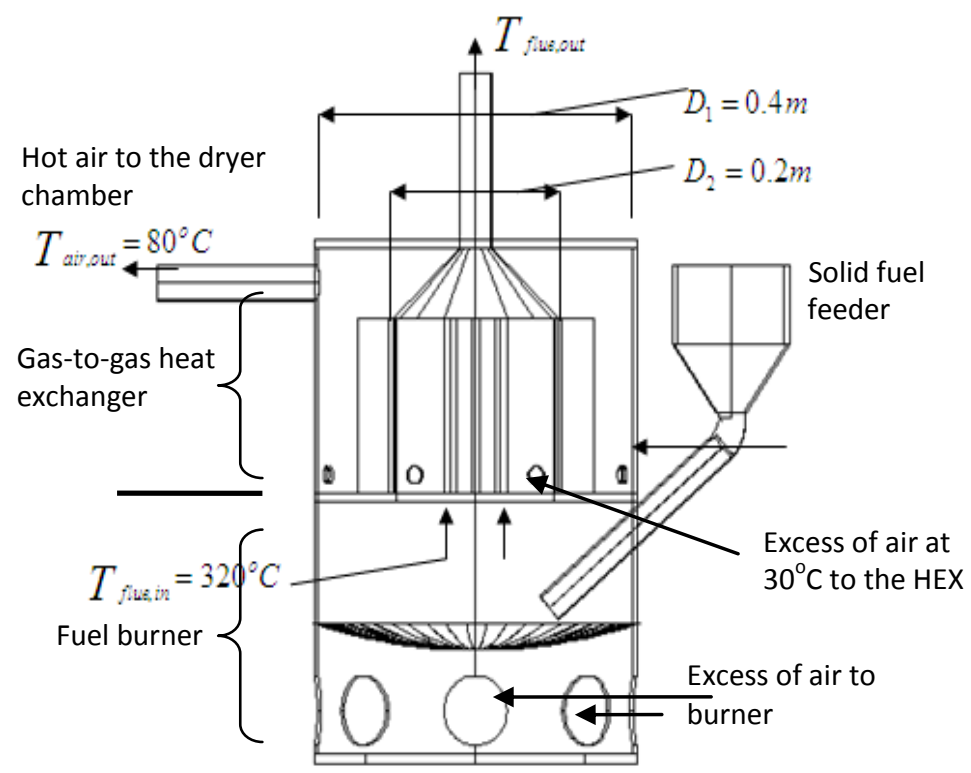

Figure 2. Sketch of the thermal backup unit comprising a solid fuel burner and gas-togas heat exchanger.

The weight was measured using a digital scale model FEJ-5000 (max $5 \mathrm{~kg}$ with $1 \mathrm{gm}$ resolution). The initial weight of the EFB product was $2.5 \mathrm{~kg}$ distributed as $0.5 \mathrm{~kg}$ in each tray. The initial moisture content was measured and found to be around $75 \%$. The weight of product was measured every hour until it reached the required final moisture content, which was $6 \%$ as recommended by (Rahim \& Suffian, 2006). The reference time of day is $9.00 \mathrm{am}$. The EFB product was dried under four different drying modes, namely, open sun drying, solar drying, TBU drying, and hybrid solar + TBU drying.

\section{RESULTS AND DISCUSSION}

The open sun drying experiment was carried out by exposing $2.5 \mathrm{~kg}$ of EFB to the same weather conditions of solar drying in the dryer. Open sun drying is common practice in Malaysia to dry products like chillies and fish. The results of the open sun drying were used as a reference for comparison with other modes.

\section{Solar Drying Mode}

In this mode, the EFB was dried using the heat source from the solar radiation. The weight reductions were measured hourly in each tray until they reached around 5 to $6 \%$ final moisture content. The results are shown in Figure 3. The results indicated that the solar drying mode required around 52 to 80 hours to dry the EFB, according to the tray location, while open sun drying required 100 hours. The rate of open sun drying is slower than solar drying as can be observed from the slope of the weight reduction results. Tray 5 took the shortest time to complete the drying since it was located at the top and was fully exposed to solar radiation, so that drying was mostly by direct solar drying. This was followed by Tray 1 since it was located just above the solar collector and the heat flow through the convection process had the highest temperature in the chamber. Tray 4 and Tray 2 stopped at nearly the same drying time since they were 
located at the interval of the heat source. Tray 3 took the longest time to dry because it was located in the middle and a portion of the solar radiation was blocked by the other trays, in addition to which the warm air from underneath was at a relatively low temperature. It can be concluded that under this mode, the trays located below Tray 5 have problems with the shadowed area. This caused a large difference between the mass reduction ratios of the trays. Generally, the drying rate in the initial 18 hours was noticed to be higher than the overall period. This trend was also reported by (Sulaiman et al., 2013) in their study of drying EFB in mixed solar mode using a dryer of their own design.

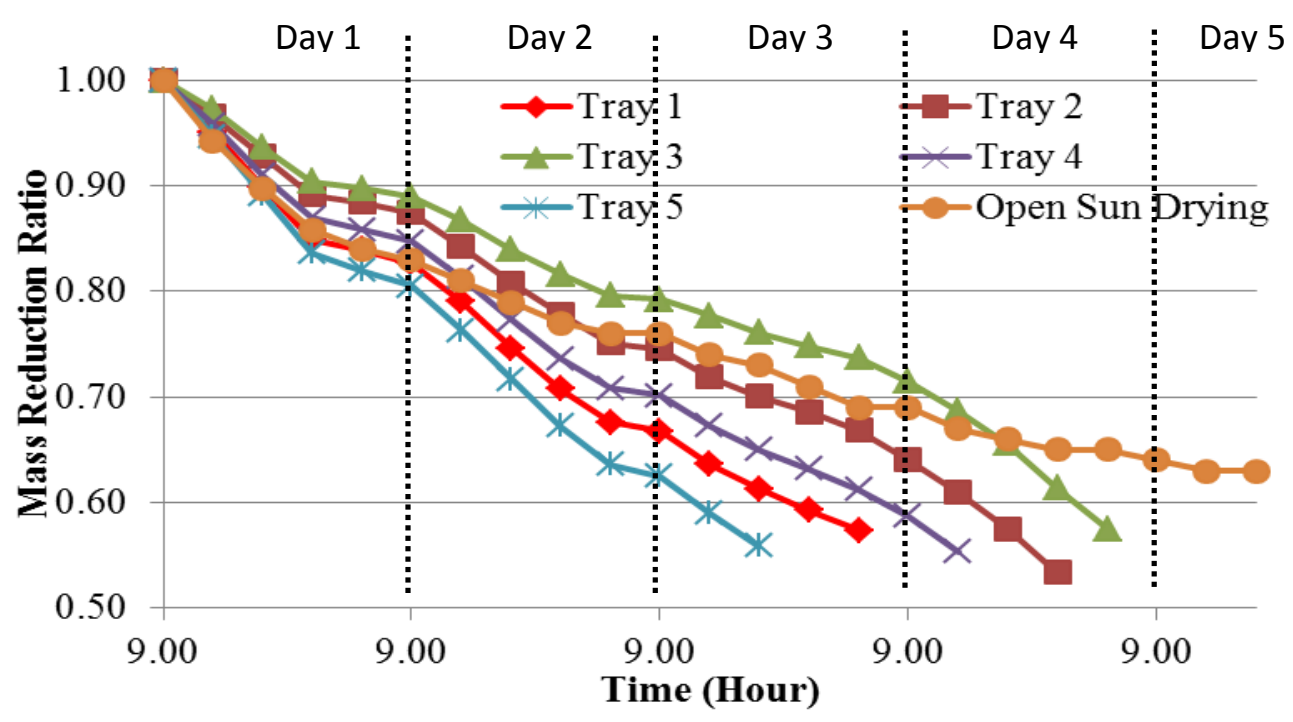

Figure 3. Drying of EFB under solar mode only

\section{Thermal Backup Drying Mode of EFB}

The EFB was dried using the hot air supplied from the TBU. The drying process was run continuously even at night since it was not affected by the presence of solar radiation. The results are shown in Figure 4. The results indicated that under thermal backup mode, the drying process took about 48 to 56 hours to dry the EFB. The ignition started at 9.00 am and the fuel feeding was continued at 2 hour intervals until $11 \mathrm{pm}$ daily.

It was observed that the lower the trays were, the faster the drying was completed since they were more exposed to the source of heat. As hot air passes through the first tray, its temperature is reduced and its moisture content becomes higher due to the mass of water transfer from the product in the lower tray. The time difference between the trays reaching the final moisture content of $6 \%$ was constant at 2 hour intervals from tray to tray. 


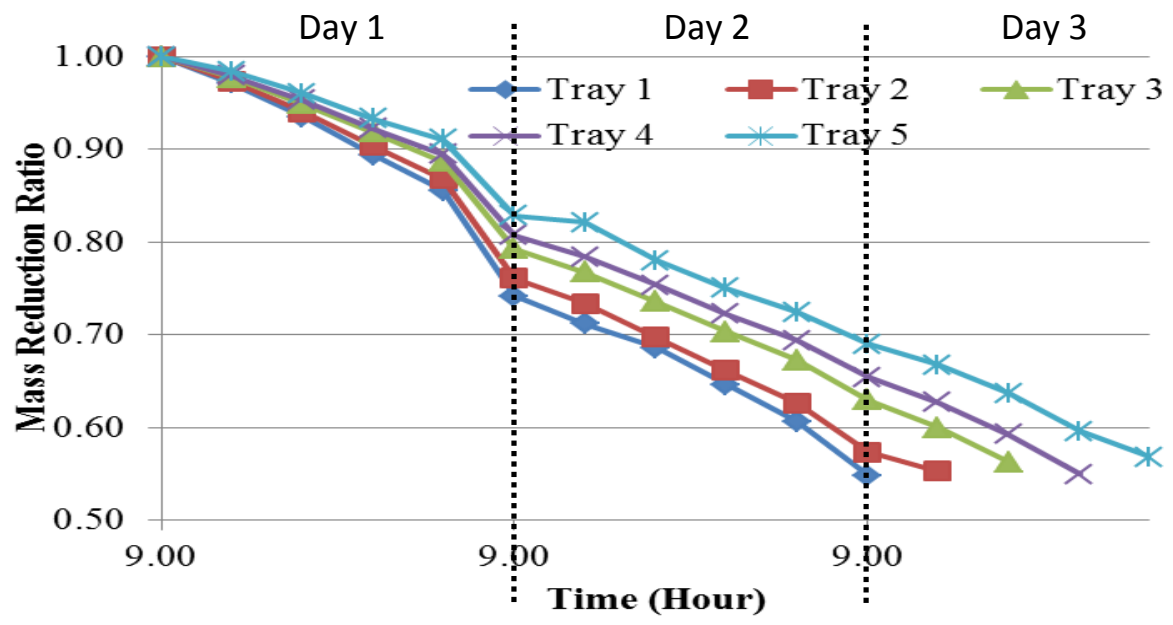

Figure 4. Drying of EFB under thermal backup mode only

\section{Hybrid Drying Mode of EFB}

The combined drying mode was conducted using solar as the source of heat and the flue from the TBU. At night, the drying process runs continuously with the presence of biomass. The results are shown in Figure 5. This hybrid mode took about 24 to 32 hours to complete the drying process. Based on the results shown in Figure 5, Tray 1 requires 24 hours to dry $0.5 \mathrm{~kg}$ of the EFB since it received continuous heat from the hot working fluid and it did not rely on the availability of solar radiation. Tray 5 and Tray 2 took 26 and 28 hours respectively to complete the drying process, followed by Tray 4 and Tray 3 at 30 and 32 hours. The location of the tray as well as the shadowed area caused the different drying rate at each tray. Overall comparisons of the different modes of EFB drying are shown in Figure 6. It can be concluded that the hybrid mode is the best mode of drying since it took the shortest periods to reach the EFB's final moisture content.

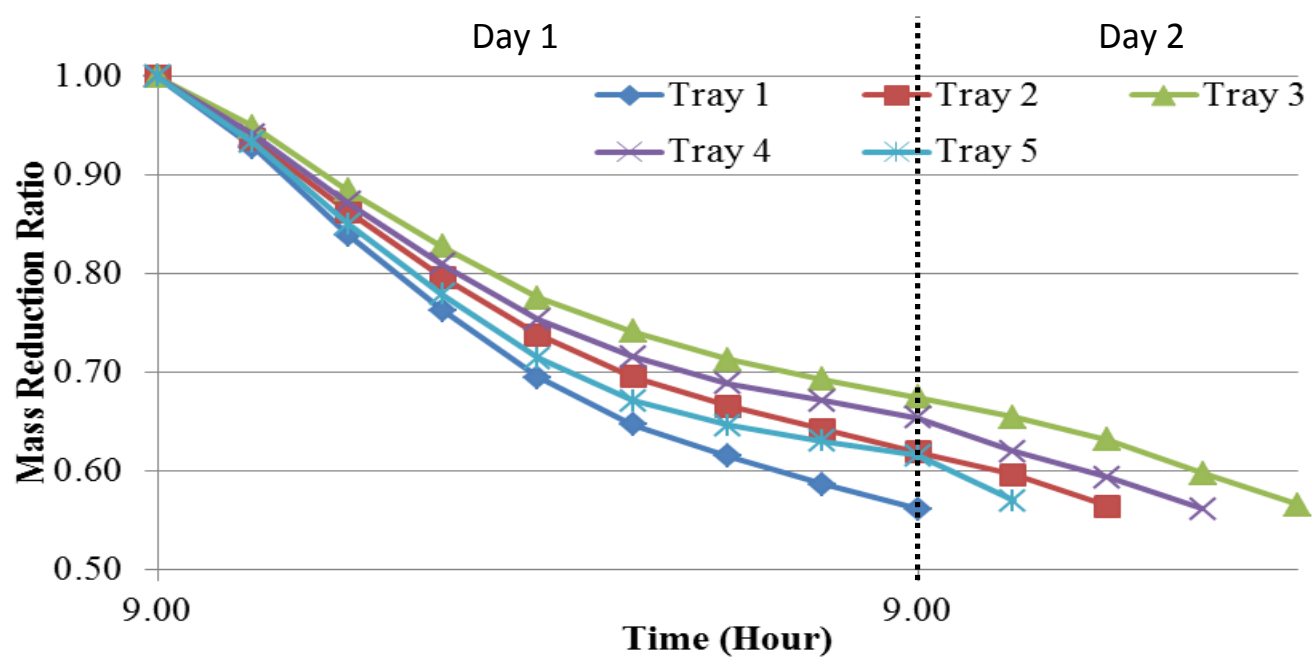

Figure 5. Drying of EFB under hybrid mode 


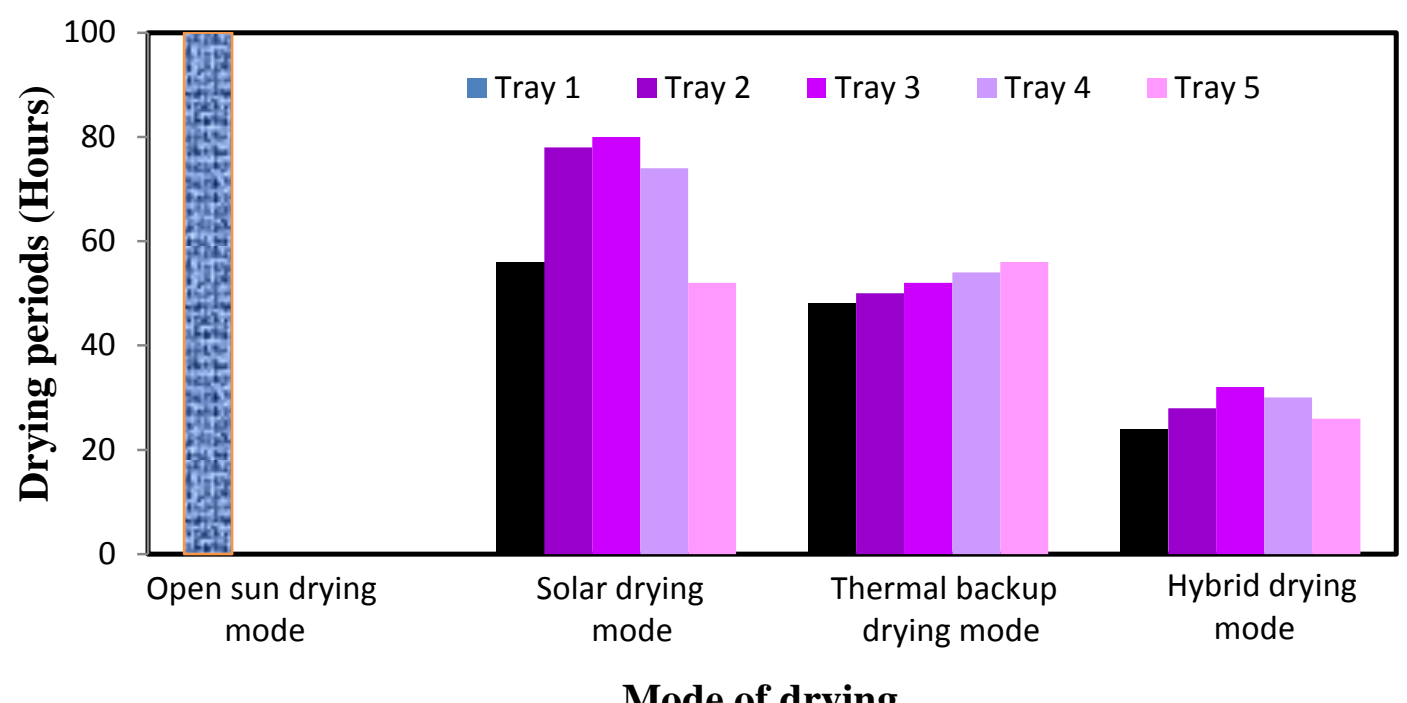

Figure 6. The overall comparison of EFB drying under different modes

\section{Drying Efficiency}

The drying efficiency, $\eta_{d}$ was calculated by considering the type of thermal input, whether from solar $(s)$, thermal backup (Naber, Siebers, Westbrook, Caton, \& DiJulio) or hybrid inside the dryer. It is dependent on the mass reduction of product in the drying time as below:

$$
\eta_{d}=\frac{M \lambda}{t\left[\left(\Sigma I_{c} A_{c}\right)_{s}+\left(\dot{m} c_{p} \Delta T\right)\right]}
$$

where:

$\Delta T=T_{\text {in }}-T_{\text {chimney }}$ is the reduction in the hot air temperature across the dryer, $I_{c}$, is the measured solar intensity at the absorber plate in $\mathrm{W} / \mathrm{m}^{2}$, and $A_{c}$ is the absorber plate area in $\mathrm{m}^{2}$.

The drying efficiency results for the EFB based on different operational modes are shown in Figure 7. The efficiency increases from open sun to hybrid drying mode. The lowest efficiencies for drying of EFB were in open sun drying, followed by solar mode, because the heat received is inconstant and depends solely on the weather conditions. The drying process took longer and was interrupted especially during cloudy days and at night. In thermal backup mode, the drying process operates continuously without being affected by weather conditions and hence resulted in higher enhancement than solar mode. It was observed that the highest efficiencies were obtained in the hybrid mode, under which the drying efficiency of EFB was $11 \%$ in 1.17 days. The drying process occurred continuously even at night since it was supported with the thermal backup unit. During the day, the heat received was higher than at night since the heat from solar was extended by the thermal backup unit. 


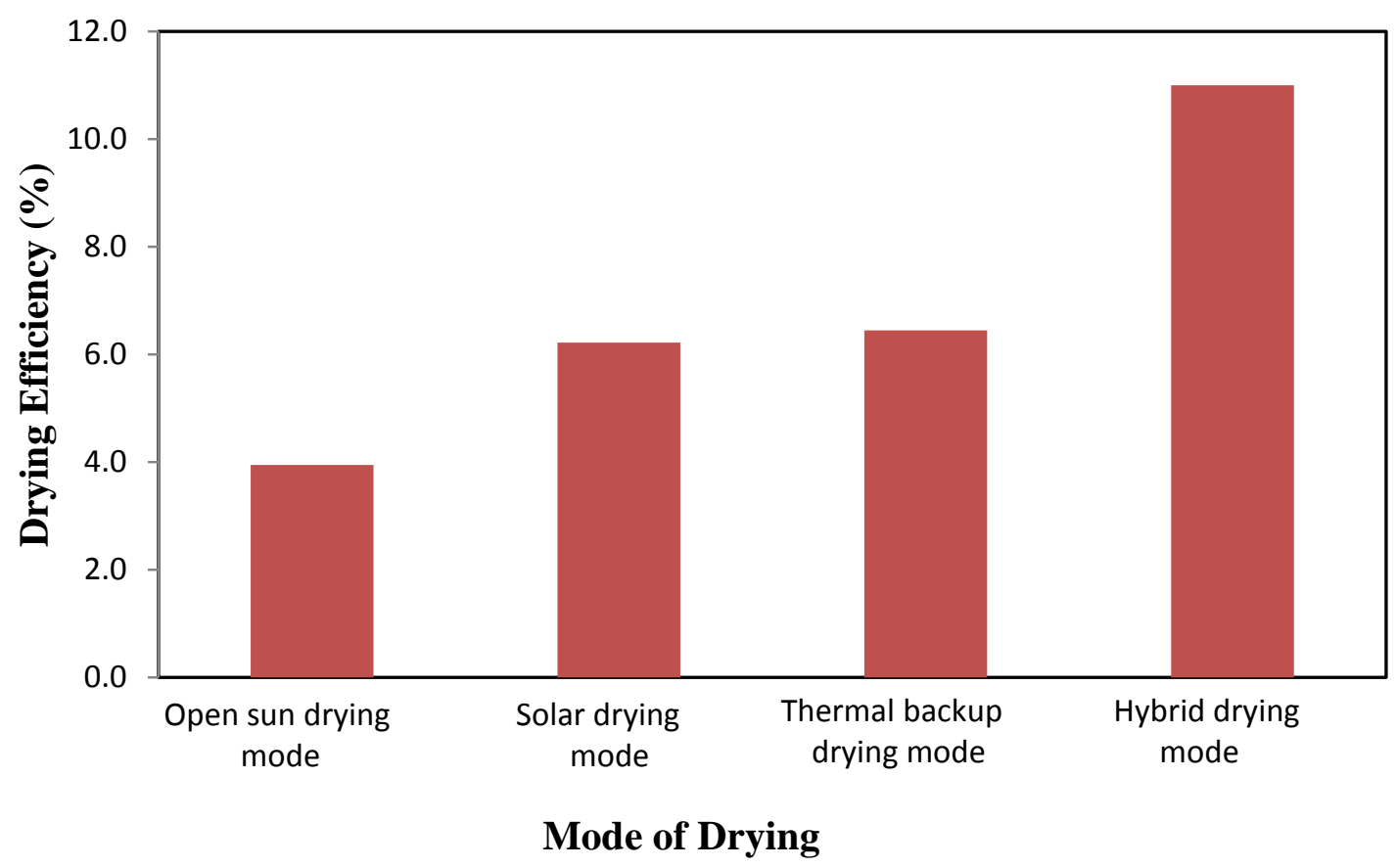

Figure 7. Comparison of drying efficiencies

\section{CONCLUSIONS}

The design and fabrication of a solar dryer integrated with a thermal backup unit is presented. The thermal backup unit comprises a solid fuel burner and a gas-to-gas heat exchanger. The solar dryer operates under direct and indirect solar radiation. The thermal backup unit can successfully supply hot air at about $70^{\circ} \mathrm{C}$. This temperature is able to maintain the drying chamber at around 50 to $60^{\circ} \mathrm{C}$. Three different drying modes of EFB are investigated and the results have shown the considerable contribution made to the enhancement of the drying process by the use of the thermal backup. The time required to dry $2.5 \mathrm{~kg}$ of EFB is 4.21 days under the open sun drying mode. This can be reduced to 1.33 days. By using the thermal backup, therefore, the drying efficiency of the EFB was enhanced by $64 \%$. The contribution of the TBU is found to be very effective. It is highly recommended to integrate solar dryers with thermal backup to achieve better performance. The measurement results revealed that the location of the tray significantly influenced the drying period. In the solar and the hybrid modes, the middle tray is found to take longer to dry the product compared to the other trays. Further investigations are recommended for other types of products, like food, fish and herbs.

\section{ACKNOWLEDGEMENT}

The authors would like to acknowledge Universiti Teknologi PETRONAS for the financial support to conduct the research under the GA scheme.

\section{REFERENCES}

Bena, B., \& Fuller, R. J. (2002). Natural convection solar dryer with biomass back-up heater. Solar Energy, 72(1), 75-83. 
Brammer, J. G., \& Bridgwater, A. V. (1999). Drying technologies for an integrated gasification bio-energy plant. Renewable and Sustainable Energy Reviews, 3(4), 243-289.

Chua, N. S. (1991). Optimal utilization of energy sources in a palm oil processing complex Seminar on Development in Palm Oil Milling Technology and Environmental Management

Energy Information Bureau (EIB) Malaysia.). Retrieved April 22, 2010, from http://eib.org.my/index.php?page=article\&item=100,136,143,152.

Hasibuan, R., \& Daud, W. R. W. (2007). Through drying characteristic of oil palm empty fruit bunch (efb) fibers using superheated steam. Asia-Pacific Journal of Chemical Engineering, 2(1), 35-40.

Madhlopa, A., \& Ngwalo, G. (2007). Solar dryer with thermal storage and biomassbackup heater. Solar Energy, 81(4), 449-462.

Mannan, A. (2008). Composting efb - empty fruit bunches of oil palm. Retrieved May 11, 2010, from http://www.etawau.com/OilPalm/EFB.htm.

Mastekbayeva, A. G., Chandika, P. B., Augustus, M. L., \& Kumar, S. (1999). Experimental studies on a hybrid dryer. Paper presented at the ISES 99 Solar World Congress, Israel.

Naber, J. D., Siebers, D. L., Westbrook, C. K., Caton, J. A., \& DiJulio, S. S. (1994). Natural gas autoignition under diesel conditions: Experiments and chemical kinetic modeling. SAE Technical Paper.

Prasad, J., Vijay, V. K., Tiwari, G. N., \& Sorayan, V. P. S. (2006). Study on performance evaluation of hybrid drier for turmeric (curcuma longa 1.) drying at village scale. Journal of Food Engineering, 75(4), 497-502.

Rahim, S., \& Suffian, M. (2006). Development of specialty particleboard from oil palm fibre., from http://info.frim.gov.my/cfdocs/infocenter/highlight.NONIRPA _2006?08\%20Rahim\%20Sudin.pdf.

Serafica, E., \& del Mundo, R. (2005). Design and qualitative performance of a hybrid solar-biomass powered dryer for fish. Paper presented at the World Renewable Energy Regional Conference, Jakarta, Indonesia.

Sulaiman, F., Abdullah, N., \& Aliasak, Z. (2013). Solar drying system for drying empty fruit bunches. Journal of Physical Science, 24(1), 75-93.

Tarigan, E., \& Tekasakul, P. (2005). A mixed-mode natural convection solar dryer with biomass burner and heat storage back-up heater. Paper presented at the Australia and New Zealand Solar Energy Society (ANZSES) Annual Conference, Dunedin NZ.

Thanaraj, T., Dharmasena, D., \& Samarajeewa, U. (2004). Development of a rotary solar hybrid dryer for small scale copra processing. Tropical Agriculture Research, 16, 305-315.

Yunus, Y. M. (2011). Development and analysis of hybrid solar dryer with biomass backup heater. (Master's), Universiti Teknologi PETRONAS. Retrieved from http://utpedia.utp.edu.my/id/eprint/3060

Yunus, Y. M., Al-Kayiem, H. H., \& Albaharin, K. A. K. (2011). Design of a biomass burner/gas-to-gas heat exchanger for thermal backup of a solar dryer. Journal of Applied Sciences, 11, 1929-1936. 